\title{
FAMÍLIAS DE CLASSES POPULARES, DESIGUALDADE SOCIAL E LITÍGIOS QUE ENVOLVEM CRIANÇAS: GARANTIA OU VIOLAÇÃO DE DIREITOS?
}

LOW INCOME FAMILIES, SOCIAL INEQUALITY AND DISPUTES INVOLVING CHILDREN: GUARANTEE OR VIOLATION OF RIGHTS?

FAMILIAS DE CLASES POPULARES, DESIGUALDAD SOCIAL Y DISPUTAS SOBRE NIÑOS: fi GARANTÍA O VIOLACIÓN DE LOS DERECHOS?

\author{
Sonia M. Gomes Sousa* \\ Jordana Pinheiro*
}

\begin{abstract}
RESUMO
Este artigo se propõe a apresentar os significados atribuídos pelos entrevistados, profissionais do Direito atuantes no Direito das Famílias e da Criança, acerca do papel desempenhado pela família nos litígios que envolvem crianças. Os profissionais entrevistados frequentemente apontaram o "fracasso" da família como motivador da intervenção judicial na vida das crianças, do excesso de exposição, da tensão provocada e da potencial formação de trauma nas crianças atendidas pelo Judiciário. Nessas entrevistas, busca-se identificar as contradições que cercam esse papel, que ora se mostra como garantia de direitos e ora como violador. Tais contradições expressam a severa distância que ainda separa a criança da concretização efetiva de políticas públicas que garantam plenamente seus direitos, sobretudo no que tange às crianças oriundas das classes populares atingidas pela desigualdade social. A análise e o alicerce teórico deste texto se norteiam pela Psicologia sócio-histórica de Vigotski, uma perspectiva crítica que admite a contradição e aspira a uma transformação das relações sociais.
\end{abstract}

Palavras-chave: Psicologia sócio-histórica. Direitos da criança. Dialética exclusão/inclusão social. Sistema de garantias de direitos. Famílias de classes populares.

\section{ABSTRACT}

This article aims to present the meanings attributed by the interviewees, law professionals working in Family and Children's Law, about the role played by the family in litigations involving children. The interviewed professionals frequently pointed the family "failures" as motivators of

\footnotetext{
"Doutora em Psicologia Social pela PUC São Paulo, professora de Psicologia na Escola de Ciências Sociais e da Saúde da PUC Goiás, psicóloga.

"* Mestra em Psicologia Social pela PUC Goiás, advogada familiarista, professora de Direito das Famílias e das Sucessōes em cursos de especialização.
} 
judicial intervention in children's lives, the excess of exposure, the resulting tension and the potential development of trauma in the children assisted by the Judiciary. The interviews aim at identifying the contradictions surrounding this role, which sometimes turns out to be either a guarantee or a violator of the rights. Such contradictions express the severe distance that still separates the child from the effective implementation of public policies that fully reassure their rights, especially with regard to children from low income classes affected by social inequality. The Sociohistorical Psychology of Vygotsky, a critical perspective that admits contradiction and aspires the transformation of social relations is the guideline to carry out the analysis as well as the theoretical base of this study.

Keywords: Sociohistorical Psychology. Child rights. Dialectic social exclusion/inclusion. System of rights and guarantees. Popular class families.

\section{RESUMEN}

Este artículo pretende presentar los significados atribuidos por los entrevistados, profesionales del derecho que trabajan en los derechos de la familia y de los niños, sobre el papel que desempeña la familia en los litigios que involucran a los niños. Los profesionales entrevistados señalaron frecuentemente los "fracasos" familiares como motivadores de la intervención judicial en la vida de los niños, del exceso de exposición, de la tensión causada y de la posible formación de trauma en los niños cuyas vidas se discuten en el poder judicial. El artículo busca identificar las contradicciones que expresan la distancia que aún separa el niño de la implementación efectiva de políticas públicas que garantizan plenamente sus derechos, especialmente con respecto a los niños de las clases populares afectadas por la desigualdad social. Tiene como referencia de análisis y fundamento teórico la Psicología sociohistórica de Vygotsky, perspectiva crítica que admite la contradicción y aspira a la transformación de las relaciones sociales.

Palabras clave: Psicología sociohistórica. Derechos del niño. Dialéctica exclusión/inclusión social. Sistema de garantías de derechos. Familias de clase popular.

\section{INTRODUÇÃO}

E

ste estudo, resultado de um recorte da pesquisa $A$ escuta das crianças em juizo: uma análise dos significados atribuídos pelos profissionais do Direito à luz da Psicologia Sócio-Histórica (Pinheiro, 2018), sustenta-se nas construções teóricas de Vigotski, com o objetivo de refletir acerca do papel da família nos litígios que envolvem crianças. Em decorrência dessa proposta, pretende-se aprofundar a problematização e contribuir para a construção do conhecimento 
necessário para apreender e compreender cientificamente o fenômeno psicossocial das relaçôes entre a sociedade, a família, a justiça e a garantia dos direitos das crianças.

Embora a criança tenha sido alçada à condição de sujeito de direitos no plano da lei, na transição das décadas de 1980 a 1990 - tanto pela Constituição Federal de 1988 e pelo Decreto no 99.710, que promulga a Convenção sobre os Direitos da Criança, quanto pelo Estatuto da Criança e do Adolescente (Lei $n^{o}$ 8.069/1990) -, observa-se que ainda persiste uma severa distância que não lhe garante plenamente seus direitos nem políticas públicas efetivas que atendam às suas necessidades biopsicossociais. Assim, a objetificação dessas medidas somente se revela aos olhos daqueles que se dedicam a uma análise crítica de seu lugar social, que, por certo, é na família.

Assim, embora ostente condição de sujeito na forma reconhecida pela lei especialmente pela Constituição Federal, pela Convenção e pelo Estatuto, desde o fim da década de 1980 -, a criança permanece em situação de assujeitamento, em posição análoga à da objetalização com a qual se buscou romper a partir da transição da doutrina menorista para a doutrina garantista (Amin, 2015, p. 51; Bernardi, 2015, p. 31), a despeito do reconhecimento que lhe fora outorgado pela lei.

O assujeitamento é ainda mais evidente entre as crianças vitimadas pela perversa desigualdade social que marca o Brasil. Segundo dados extraídos da Síntese de Indicadores Sociais (SIS), publicada pelo Instituto Brasileiro de Geografia e Estatística (IBGE) (2018), ao analisar o tema "pobreza" com diferentes medidas para verificar a condição social dos brasileiros no período entre 2016 e 2017, $12,5 \%$ da população brasileira de 0 a 14 anos vivia na extrema pobreza, e 43,4\%, na pobreza no ano de 2017. Em números absolutos, eram, naquele ano, 5,2 milhões de brasileiros de 0 a 14 anos na extrema pobreza, e 18,2 milhões na pobreza. Para o IBGE, é considerado em situação de extrema pobreza quem dispóe de menos de US\$1,90 por dia, o que equivale a aproximadamente R\$ 140 por mês; já a linha de pobreza é de rendimento inferior a US\$ 5,5 por dia, o que corresponde a cerca de $\mathrm{R} \$ 406$ por mês. A SIS mostrou outro dado assombroso: entre todos os grupos etários, o percentual de pobreza por contingente populacional tem maior concentração em crianças e jovens.

O mesmo estudo ainda relacionou a pobreza, as crianças e suas famílias, analisando a prevalência da pobreza, com base nas características das pessoas de referência dos domicílios. Do total de moradores em domicílios em que a pessoa de referência era uma mulher sem cônjuge e com filhos de até 14 anos, 56,9\% estavam abaixo dessa linha. Se a responsável pelo domicílio fosse uma mulher 
preta ou parda (igualmente sem cônjuge e com filhos no mesmo grupo etário), essa incidência subia para $64,4 \%$.

Assim, a preocupação acerca do fenômeno psicossocial das relações entre a sociedade, a família, a justiça e as crianças se justifica visto que, apesar dos inegáveis avanços, notadamente no plano da lei positivada, observam-se injustiça social e retrocessos no horizonte.

\section{METODOLOGIA DA PESQUISA}

Na busca pela compreensão dialética do papel da família nos litígios, optou-se, na pesquisa empírica, pela realização de entrevistas individuais com profissionais do Direito com atuação em processos judiciais que envolvessem crianças e adolescentes: Maria Augusta e Paula, representantes do Ministério Público (MP); Gustavo e Murilo, da Defensoria Pública Estadual (DPE); e Adriana e Marcela, da Ordem dos Advogados do Brasil (OAB). Para entrevistá-los, elaborou-se um roteiro não fechado que possibilitasse que eles (aqui nomeados ficticiamente, em respeito à privacidade individual) se expressassem mais livremente e acessassem seus repertórios de compreensão dos temas propostos para a discussão. Entre esses temas destacaram-se: os significados de infância e criança; sua participação social e a forma de sua escuta no processo judicial; o grande contingente de açóes judiciais que envolvem crianças; o potencial conflito entre família e Estado na tutela dos interesses da criança; e a percepção estatal de que certas famílias seriam inaptas para o desempenho de seu papel.

O tema discutido nesta pesquisa, que envolve, ao mesmo tempo, sujeitos socialmente tidos como frágeis (as crianças) e sujeitos socialmente fortes, poderosos e prestigiados (os profissionais do Direito que protagonizam as relaçôes dentro dos tribunais), demandou delicadeza em sua análise e tratamento. Com amparo na dialética, realizou-se a leitura do objeto de estudo e dos referenciais teóricos usados para tentar construir uma interpretação que buscasse, inicialmente, comportar as compreensões do Direito e da Psicologia sobre o tema discutido. Essa interface interdisciplinar acabou por agregar o conhecimento advindo de outras ciências, como a História e a Sociologia, voltadas ao estudo da infância.

Vale ressaltar que, na perspectiva vigotskiana (Vigotski, 1989; 2000), é por meio da linguagem que o homem é constituído, sendo, portanto, constituinte de outros indivíduos. Torna-se, assim, fundamental registrar e analisar a linguagem falada, pois não apenas o que se diz importa, mas também como se diz, do que se diz e o que deixa de ser dito. 
$\mathrm{Na}$ escuta dos sujeitos entrevistados, concretamente considerados com todas as suas singularidades, buscou-se escutar também aquilo que de mais amplo eles representam: o próprio sistema de garantias de direitos, seus avanços e seus retrocessos, seus acertos e seus erros, suas conquistas e suas falhas. Essa proposta de análise se fortaleceu por meio da adoção do conceito de "sujeito representante": o sujeito não se expressa sozinho, mas expressa sua instituição bem como toda a rede de proteção e atenção que representa (Sousa, 2001).

A escolha desse percurso (e, mais do que isso, a exigência do próprio caminho trilhado) foi feita pelo enfrentamento das contradições do papel da família nos litígios que envolvem crianças bem como das tensões entre as garantias e as violações dos direitos vislumbradas.

\section{DO PAPEL DA FAMÍLIA NOS LITÍGIOS QUE ENVOLVEM CRIANÇAS}

Nas entrevistas, quando perguntados acerca das ações judiciais que envolvem crianças (por exemplo, ações de guarda, visitas, alimentação, destituição do poder familiar, indenização por abandono afetivo, adoção), todos os sujeitos pesquisados levantaram a questão do papel da família. É importante salientar que todos eles, operadores no âmbito do sistema de Justiça, atribuíram uma responsabilidade preponderante à família, que, segundo eles, permitiu que aquela criança chegasse a ter sua vida discutida em juízo.

Essa família, que, de acordo com os entrevistados, não protegeu a criança tanto quanto deveria, apareceu em quase todas as falas quando perguntados sobre como viam a criança no processo judicial. Um deles levantou, inicialmente, a dialética apresentada na introdução deste artigo (previsão de direitos versus efetivação desses mesmos direitos) e a estendeu à dimensão familiar:

A realidade que eu vejo, não só dentro do Direito, é que, infelizmente, apesar de tudo que já se estudou no mundo, a criança passou a ocupar um espaço maior na família, na sociedade como um todo, mas que esse espaço não é pleno de cidadania. É como uma condescendência do adulto para com aquela criança. Mas o exercício pleno da cidadania da criança eu não vejo ainda efetivado, ou eu vejo efetivado em poucas situaçôes (Maria Augusta, MP).

A respeito, mais especificamente, da dimensão processual, ela atribuiu à família a responsabilidade pelas crianças, ao tratá-las como centros, ou focos, de suas disputas pessoais levadas a juízo:

O que eu vejo é que, quando o processo judicial começa, o foco é o interesse de uma criança ou de um adolescente. Ele realmente se inicia com esse foco, a criança e o adolescente, a 
princípio [. . . ]. Só que, no curso do processo, você começa a ver que o interesse verdadeiro naquela questão pode não estar realmente na criança e no adolescente, mas em conflitos instalados naqueles que estão na disputa [. . .]. Ou dos responsáveis, ou pai, ou mãe, ou avô, etc. (Maria Augusta, MP).

Marcela (OAB), por sua vez, levantou a temática da família quando falou da invisibilidade da criança que, para ela, iniciar-se-ia e se intensificar-se-ia entre os seus mais próximos, aqueles mesmos que a cercam, para então repercutir na Justiça:

Eu a vejo invisível. Ora ela é tratada como alguém que devesse cumprir o seu papel dentro de uma família. Ora eu a vejo como alguém que atrapalha esse papel dentro de uma família. Isso, no Judiciário, chega exatamente assim. É como se o Judiciário fosse o grande senhor entendedor dessa criança, que está numa fase de infância, e o Judiciário acha que entende essa família o suficiente para dizer: "Olha, o que você necessita é isso, porque eu acho que é isso. E o que você queria, agora, não é a hora de você querer, porque eu acho que não é agora de você querer". Então eu vejo ela angustiada (Marcela, OAB).

Diante dessas falas, importa discorrer acerca da responsabilidade atribuída pelos entrevistados à família pela forma como as crianças acabam tendo suas vidas discutidas em juízo. Quando perguntados sobre esse lugar da criança no processo judicial, os sujeitos sustentam que, se a família (que é quem deveria proteger essa criança em primeiríssimo lugar) não cumpriu sua missão, não caberia, tampouco, ao operador do Direito a responsabilidade de protegê-la.

Talvez esse raciocínio acabe por autorizar aos profissionais do Direito a possibilidade de se eximirem de sua responsabilidade pela vida da criança discutida no processo. Ora, se essa criança já figura no processo com a imagem de "abandonada" pelos seus principais cuidadores, por que aqueles profissionais, muito mais distantes dela, deveriam tratá-la com todo zelo e cuidado? No entanto o que uma criança amada, protegida, bem cuidada e com todos os seus direitos garantidos faria em um processo judicial? Não seria o processo justamente para corrigir equívocos, falhas, descasos, desfeitas, agressões, violências e erros perpetrados contra a criança?

Além disso, é impossível atribuir às famílias ditas "desestruturadas" uma total responsabilidade pelo seu desmoronamento, principalmente porque elas margeiam "os núcleos de poder da sociedade". Afinal, são essas famílias, sobretudo, de que tratam os processos judiciais. "Esta concepção introduz a ética e a subjetividade na análise sociológica da desigualdade, ampliando as interpretações legalistas e minimalistas de inclusão como as baseadas em justiça social e restritas à crise do Estado" (Sawaia, 2017, p. 8). 
A respeito das famílias consideradas "desestruturadas", Rizzini, Rizzini, Naif e Baptista (2007, p. 18) afirmam:

Essas famílias ainda são muitas vezes retratadas como incapazes de criar os seus filhos. O que se deseja ressaltar aqui é o equívoco na compreensão do problema, cuja origem ficou, não por acaso, reduzida à incapacidade dessa família. $\mathrm{Na}$ atualidade, ressaltem-se as competências das famílias, mas, na prática, com frequência, cobra-se dos pais que deem conta de criar seus filhos, mesmo que faltem políticas públicas que assegurem condições mínimas de vida digna: emprego, renda, segurança e apoio para aqueles que necessitem.

As noções de família "estruturada" e de família "desestruturada" encontramse bem presentes na compreensão social que se tem de família. $\mathrm{Na}$ fala de Paula (MP), quando perguntada sobre como via a criança na sociedade, isso se evidencia:

Infelizmente, titular de muitos direitos, porém extremamente carente do exercício desses direitos. É assim que eu vejo a criança hoje. Mesmo aquelas que estão em famílias ditas estruturadas. Eu falo que não estejam em situação de risco. Então, mesmo aquelas que estão em famílias estruturadas, eu vejo todo o conflito das relações familiares. Mesmo nessas famílias, eu vejo a criança carente do exercício dos seus direitos (Paula, MP).

Historicamente, a família nem sempre foi a mesma e, por conseguinte, nem sempre ofereceu a mesma qualidade de base de apoio às suas crianças. Em um mesmo tempo histórico (por exemplo, na contemporaneidade brasileira), existem múltiplas possibilidades de constituição, ou não, dessas denominadas "bases de apoio". É na relação entre o universal (normas, costumes, valores, ideologias) e o particular de cada grupo familiar especificamente tomado (história do grupo familiar, afetividade, subjetividades dos sujeitos) que as bases de apoio se constituem ou deixam de se constituir. Não se pode, por exemplo, esquecer a dimensão de exclusão perversa da sociedade que impede, por diversos processos, o acesso a uma vida digna, tanto material quanto afetiva e emocional (Sousa \& Peres, 2002).

Ignorar a dimensão perversa da sociedade e atribuir à família que não conseguiu cumprir com a determinação sociolegal que lhe foi imputada (a de proteger seus filhos, quaisquer que fossem as condições externas) seria excluí-la da possibilidade de receber um tratamento digno na sociedade e no Judiciário. Essa exclusão, sutil e dialética, profundamente estudada por Sawaia (2017, p. 9), "É um processo complexo e multifacetado, uma configuração de dimensões materiais, políticas, relacionais e subjetivas", não podendo ser simploriamente reduzida a "uma coisa ou um estado, é um processo que envolve o homem por inteiro e suas relações com os outros". 
Nas falas de Murilo (DPE), a dimensão da desigualdade social que assola as famílias e as crianças das classes populares é bastante evidente. Perguntado sobre como enxerga a criança na sociedade, especialmente a brasileira, ele destaca a dialética já tratada e atribui à desigualdade social as raízes de tamanha contradição:

Apesar de toda evolução, em termos da rede de proteção, do sistema de proteção, ainda vejo a criança sendo tratada não como um sujeito de direitos, como deveria ser, e, às vezes, negligenciada na sua condição peculiar, enquanto pessoa em desenvolvimento. Assim, ainda hoje, a gente encontra índices altíssimos de trabalho infantil, mortalidade, subnutrição, evasão escolar, o que evidencia que, da parte do Estado, a sua obrigação de garantir o desenvolvimento, tratar a criança como prioridade absoluta, não tem sido feita. Acredito que o acentuado índice de desigualdade social contribui para esse processo. De modo que há ainda uma distinção de crianças e famílias pobres e crianças de famílias ricas. As crianças de famílias pobres continuam à margem dos direitos mais fundamentais, direito à saúde, direito à educação, direito ao respeito, à dignidade, enquanto as crianças de famílias de melhores condiçôes, essas, sim, já são vistas com uma certa prioridade (Murilo, DPE).

\section{Relacionando às dimensões da família e da desigualdade, que inegavelmente} não podem ser estruturantes, Murilo continua:

Essas crianças das classes menos favorecidas, que são as crianças que pertencem às famílias que a Defensoria Pública assiste, são negligenciadas em todos os lugares onde elas estão. Elas são negligenciadas pelas famílias, elas são negligenciadas nas comunidades. Nas comunidades, por exemplo, elas são utilizadas, desde pouca idade, para tráfico de drogas, elas são corrompidas, sofrem violência e negligência nas escolas. Em algumas escolas, eu não posso dizer que é a regra esse tratamento, mas que acontece, e acontece com frequência. Muitas vezes, no âmbito da própria rede de proteção. E aí a gente chega ao Poder Judiciário, nossa área, onde essas crianças também sofrem. Sofrem preconceito. Às vezes, um preconceito no sentido de que "essa criança tem que ser protegida sendo afastada de sua família pobre", porque se ela não tiver oportunidade de ser colocada em uma família rica, o futuro dela é incerto e ela está fadada ao fracasso (Murilo, DPE).

$\mathrm{Na}$ fala acima transcrita, a dimensão da desigualdade social (nomeada pelo sujeito entrevistado como "classe menos favorecida") aparece acompanhada das ideias de negligência (nas famílias e nas comunidades), de utilização da criança (remetendo-se às ideias de objetalização e assujeitamento já tratadas), violência, tráfico de drogas e preconceito. Ora, a perversa realidade vivenciada pelas famílias das classes populares não se deve à sua falência pessoal, única, individual, mas à expressão de uma organização social excludente que evidencia a dimensão de classe social e, obviamente, perpassa as relações familiares.

Assim, a significação social que se tem dessas famílias, não raro vistas como "incapazes" de criar os seus filhos, não somente é equivocada, mas 
também perversa. Ao reduzir, não por um acaso, a compreensão do problema à "incapacidade" da família, essa significação evidencia a incompreensão da dimensão de classe social pela Justiça.

Para refletir sobre essas questôes, a psicologia sócio-histórica procura ir além da facticidade e olhar as mediaçóes que configuram o particular da desigualdade social brasileira, a fim de não cair na inação, em fundamentalismos teleológicos ou no seu contrário, no pragmatismo adaptador, esquecendo a opressão do Estado e a exploração capitalista (Sawaia, 2014, pp. 7-8).

Nessa esteira, Sawaia (2017, pp. 8-9) ainda sustenta que se deve combater a tentadora ideia de culpabilização individual, propagadora de um sistema perverso de desqualificação social de alguns:

$\mathrm{Na}$ análise psicossocial, essa lógica dialética inverte a ideia de inclusão social, desatrelando-a da noção de adaptação e normatização, bem como de culpabilização individual, para ligálas aos mecanismos psicológicos de coação. A lógica dialética explicita a reversibilidade da relação entre subjetividade e legitimação social e revela as filigranas do processo que liga o excluído ao resto da sociedade no processo de manutenção da ordem social, como por exemplo o papel central que a ideia de coletividade desempenha no mecanismo psicológico principal da coação social nas sociedades onde prevalece o fantasma do uno e da desigualdade, que é o de culpabilização individual. O pobre é constantemente incluído, por mediçôes de diferentes ordens, na coletividade que o exclui, gerando o sentimento de culpa individual pela exclusão.

Parece haver, assim, uma grande contradição, ou paradoxo, no fato de que, se cabe à família exercer essa função primordial de proteção da criança e ela não o faz, constrói-se uma justificativa para que o restante da sociedade também não o faça, aí inclusos os objetivamente imbuídos dessa função. Mais que isso, parece haver nesse mecanismo de responsabilização individual uma importante artimanha de exclusão, de modo que o Judiciário só realmente incluiria acolhendo, protegendo e ouvindo aquela criança e, concomitantemente a ela, aquela família que não falhasse no cumprimento de seus deveres. Ora, de certo que aqueles que chegam a ter suas vidas e suas questôes mais íntimas discutidas em juízo não se enquadrariam nesse alto padrão de exigência: o de não terem falhado. Em se tratando deles, ficaria a Justiça também legitimada a falhar?

Nesse contexto, percebe-se a frequente fragilização das famílias, em dicotomia com o fortalecimento do Judiciário no desempenho de seu papel decisório. É o que se nota na fala de Adriana (OAB):

Porque o único arbítrio que nós temos, a única pessoa que pode balizar essa relação e proteger essa criança é o juiz. Nós não temos outro. Nós não estamos mais em um mundo em que a gente possa se dar ao luxo de pensar que os maiores protetores das crianças são seus 
pais. Não são mais, não são mais. Eles não estão preparados mais para ser pais e mães. Eles usam seus filhos, violentam psicologicamente e emocionalmente seus filhos. A quantidade de violência física e sexual é impressionante dentro das casas, por pessoas da família. Não são mais esses protetores com os quais a gente pode contar de olhos fechados.

É impossível, nesse ponto, deixar de insistir que, na lógica de responsabilização, as famílias de classes populares ocupem um lugar de acentuada crítica e discriminação, sendo consideradas, não raro, "incapazes" de educar crianças e adolescentes.

Para Sousa e Peres (2002), a ideologia difundida secularmente em nosso país "De que famílias pobres são 'desorganizadas' e 'violentas' pode ter favorecido o movimento histórico de colocá-las à margem do processo de educação dos filhos, muitas vezes delegado a instituiçôes públicas e privadas" (p. 68). Sobre a delegação do processo de educação, as autoras assim sustentam:

A institucionalização das crianças pobres é uma forma de negar às famílias o direito de exercer o papel de sujeitos na educação dos filhos, de assumir e enfrentar as contradiçóes às quais se encontram submetidas no seu cotidiano e, portanto, o direito de atualizar e de desenvolver suas potencialidades (Sousa \& Peres, 2002, p. 69).

Ao tratarem das "experiências de promoção do direito à convivência familiar e comunitária no Brasil”, Rizzini et al. (2007, p. 18) ressaltam o erro da responsabilização das famílias, que não podem ser cobradas ante a ausência de políticas públicas contundentes que assegurem condições mínimas de vida digna: emprego, renda, segurança e apoio para aqueles que delas necessitem. Enfim, às famílias parece faltar apoio para o enfrentamento de seus conflitos, principalmente daqueles advindos de seus momentos de transição, a exemplo das situações geradas pelo divórcio e pelo compartilhamento da guarda dos filhos.

Sousa e Peres (2002) defendem ainda a necessidade de apoio e intervenção, mas ressaltam que essa intervenção precisa recair sobre seus recursos e potencialidades e não somente sobre suas dificuldades e problemas. As convencionais intervenções sociofamiliares do Estado, muitas vezes autoritárias, devem ser substituídas por medidas participativas de coconstrução dos sistemas familiares e político-sociais, com base em programas de educação e de ação com foco nas famílias em si mesmas, na interação entre seus membros e na interação entre elas e outros níveis do macrossistema.

Acerca da ideia que se tem de incapacidade das famílias pobres, Gustavo (DPE) respondeu afirmativa e enfaticamente quando foi perguntado se o afastamento das crianças de suas famílias e sua consequente institucionalização seguiria algum padrão: 
Tem. Tem. São crianças pobres. Aqui em Goiânia, está muito relacionado com essas habitações populares. Está muito relacionado com isso. Aquela senhorinha que acabou de entrar aqui é um caso do Santa Rita, que é uma "invasão", como ela mesma diz. São habitações populares. E isso repercute diretamente no ato infracional e vai repercutindo, repercutindo... E a gente tem vivenciado isso. O ideal até seria fazer uma pesquisa disso futuramente. A questão da cor sem dúvida nenhuma também... Mais crianças negras (Gustavo, DPE).

Com base nessa fala, é possível concluir que a realidade que cerca a infância judicializada, por mais perversa que seja, alcança dimensões maiores e de mais profunda crueldade quando se trata da criança pobre que reúne, em um só sujeito, vulnerabilidades e fragilidades de toda ordem. Evidencia-se, assim, a consequência da reunião e da intersecção de diversas formas de dominação, discriminação e exclusão (a exemplo das dimensões de classe, raça e gênero), bem abordada pela teoria da interseccionalidade.

O Brasil, especialmente pelo delicado momento vivenciado, conta com imenso contingente de crianças e famílias em situação de peculiar invisibilidade. É preciso (e mais do que isso, é forçoso) reconhecer os avanços já alcançados (de trinta anos para cá), com a promulgação do Estatuto da Criança e do Adolescente, com as diretrizes constitucionais de 1988 e com a ratificação das principais legislações internacionais concernentes à criança e ao adolescente. Esses avanços, contudo, não foram suficientes para o alcance de um novo status social, de verdadeiro compromisso e respeito com as situações que envolvem as temáticas da família e da infância, inclusive em âmbito judicial. Elas, a infância e a criança, continuam permeadas por noções de fragmentação, enfraquecimento, assujeitamento e excessiva responsabilização da família, sobretudo quando de classes populares.

\section{CONSIDERAÇÕES FINAIS}

Há mais de vinte anos da publicação de $O$ século perdido: raizes históricas das políticas públicas para a infância no Brasil (originalmente escrito em 1997), a autora, Irene Rizzini, defendia a elaboração de "um pleito para que não se perdesse mais um século entre discursos e promessas que se esvaem e retóricas que não se afinam com as ações" (Rizzini, 2011, p. 16). Contudo se observa uma enorme distância entre o que se dispõe, especialmente na lei, e o que se pratica. Com isso, inviabiliza-se a garantia efetiva de direitos às crianças e aos adolescentes, historicamente esquecidos no Brasil, um país marcado por uma perversa cultura de fortes raízes menoristas que perpassam o lugar social da criança, da família, no âmbito da Justiça. 
$\mathrm{Da}$ análise atenta da realidade social em que estão inseridas as crianças, os questionamentos crescem: terão surtido efeitos as cartas, convenções e estatutos promulgados nas décadas da esperança? Terá a normalização sido suficiente para garantir os avanços almejados? Terá o império da lei cumprido sua missão no sentido da real efetivação dos direitos das crianças? Será hoje a doutrina da proteção integral, inaugurada no fim da década de 1980, uma realidade perceptível?

A respeito da relação socialmente construída, e não naturalmente posta, Sawaia (2017) caminha além, ao analisar e reforçar o traço perverso da dialética exclusão/inclusão. Por vezes, inebria todos, ao transparecer que o direito posto formalmente existe, quando, na verdade, ele não passa de mera retórica. Esse fenômeno se dá conforme, diante da existência da positivação, o Estado e as forças sociais se desresponsabilizam pelo processo de sofrimento que impingem aos excluídos, entre eles as crianças.

É no sujeito que se objetivam as várias formas de exclusão, a qual é vivida como motivação, carência, emoção e necessidade do eu. Mas ele não é uma mônada responsável por sua situação social e capaz de, por si mesmo, superá-la. É o indivíduo que sofre, porém esse sofrimento não tem a gênese nele, e sim em intersubjetividades delineadas socialmente. Dessa forma, se os brados de sofrimento evidenciam a dominação oculta em relaçôes muitas vezes consideradas como parte da natureza humana, o conhecimento dos mesmos possibilita a análise de vivência particular das questōes sociais dominantes em cada época histórica; em outras palavras, da vivência do mal que existe na sociedade (Sawaia, 2017, pp. 100-101).

Nesse reconhecimento, nota-se que, apesar de devidamente positivados, os direitos das crianças continuam sendo negligenciados, ignorados, suplantados. São direitos os mais diversos, imanentes à criança e à sua altiva existência, tais como: o direito de ser sujeito e não objeto; o de estudar desde a tenra infância; o de receber assistência em relação à saúde física e psicológica; o de permanecer ao lado de sua família.

A lei, embora acerte ao expressar em seus códigos a garantia de direitos (sobretudo os que envolvem diretamente o tema tratado neste artigo: o direito à convivência familiar e comunitária, e o privilégio da família natural), não consegue, de fato, garanti-los. Não se pode negar ser esse um movimento contraditório que muito interessa à Psicologia Sócio-Histórica: tem-se um direito, tem-se a expressão dele, sem, contudo, vislumbrar-se sua real efetivação.

Pode-se dizer que o Brasil abandonou a doutrina menorista apenas sob o ponto de vista formal. Historicamente, a criança nunca ocupou, e ainda não ocupa, um lugar social de verdadeiro respeito aos seus direitos. Escancara-se assim uma grande distância entre as disposições do ordenamento jurídico brasileiro, 
que se diz primar pela criança e pela sua proteção, e as práticas profissionais e institucionais perpetradas pelos órgãos do Estado responsáveis pela observância e cumprimento da ordem jurídico-legal.

Por fim, com base nas práticas sociais e jurídicas, vê-se que a perspectiva menorista retorna, cotidianamente, na forma de sua dimensão histórica, não suplantada pela noção de justiça construída nos anais da Justiça. Explícita está, portanto, a contradição que assombra o papel da família nos litígios que envolvem crianças. Neles se expressa a profunda desigualdade social de nosso país. Assim, esse tema exige uma densa articulação de compreensões que trabalhem, em cooperação, para desfechos mais humanos, mais afetuosos e mais dignificantes para a criança e a família. 


\section{REFERÊNCIAS}

Amin, A. R. (2015). Evolução histórica do direito da criança e do adolescente. In K. R. F. L. A. Maciel. (Coord.), Curso de direito da criança e do adolescente: aspectos teóricos e práticos. (pp. 3-10). (8a ed. rev.). São Paulo: Saraiva.

Bernardi, D. C. F. (2015). A construção de um saber psicológico na esfera do Judiciário paulista: um lugar falante. In E. T. Fávero, M. J. R. Melão, M. R. T. Jorge (Orgs.), O Serviço Social e a Psicologia no Judiciário: construindo saberes, conquistando direitos. (pp. 30-35). (5a ed.). São Paulo: Cortez.

Constituição da República Federativa do Brasil (1988). (1988). Brasília: Senado. Recuperado a partir de www.planalto.gov.br/ccivil_03/constituicao/ constituicao.htm

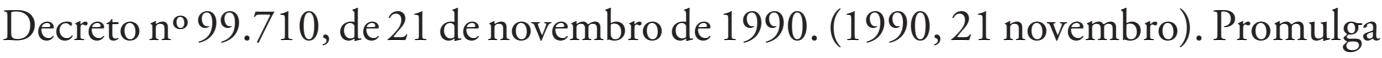
a Convenção sobre os Direitos da Criança. Diário Ofıcial da União, Brasília. Recuperado a partir de www.planalto.gov.br/ccivil_03/decreto/1990-1994/ d99710.htm

Instituto Brasileiro de Geografia e Estatística. (2018). Sintese de indicadores sociais 2018: uma análise das condiçôes de vida da população brasileira. Rio de Janeiro: IBGE. Recuperado a partir de https://agenciadenoticias.ibge.gov.br/ media/com_mediaibge/arquivos/ce915924b20133cf3f9ec2d45c2542b0.pdf

Lei no 8.069, de 13 de julho de 1990. (1990, 13 julho). Dispõe sobre o Estatuto da Criança e do Adolescente e dá outras providências. Diário Oficial da União, Brasília. Recuperado a partir de www.senado.gov.br/ccivil_03/leis/2002/ L10406.htm

Pinheiro, J. C. (2018). A escuta das crianças em juizo: uma análise dos significados atribuidos pelos profissionais do Direito à luz da Psicologia sócio-histórica. (Dissertação de Mestrado). Pontifícia Universidade Católica de Goiás, Programa de Pós-Graduação Stricto Sensu em Psicologia, Goiânia.

Rizzini, I. (2011). O século perdido: raizes históricas das políticas públicas para a infância no Brasil. (3a ed.). São Paulo: Cortez.

Rizzini, Irene; Rizzini, Irma, Naiff, L., \& Baptista, R. (2007). Acolhendo crianças $e$ adolescentes: experiências de promoção do direito à convivência familiar $e$ comunitária no Brasil. (2a ed.). São Paulo: Cortez; Brasília: Unicef/Ciespi; Rio de Janeiro: PUC-Rio. 
Sawaia, B. B. (2014). Transformação social: um objeto pertinente à Psicologia social? Psicologia \& Sociedade, 26(num. esp. 2), 4-17.

Sawaia, B. B. (Org.). (2017). As artimanhas da exclusão: análise psicossocial e ética da desigualdade social. (14a ed.). Petrópolis: Vozes.

Sousa, S. M. G. (2001). Prostituição infantil e juvenil: uma análise psicossocial do discurso de depoentes da CPI. (Tese de Doutorado). Pontifícia Universidade Católica de São Paulo, Faculdade de Psicologia, São Paulo.

Sousa, S. M. G., \& Peres, V. L. A. (2002). Famílias das camadas populares: um lugar legítimo para a educação/formação dos filhos. O Social em Questão: Revista do Programa de Mestrado em Serviço Social da PUC-Rio, 6(7), 63-74.

Vigotski, L. S. (1989). Pensamento e linguagem. São Paulo: Martins Fontes.

Vigotski, L. S. (2000, julho). Manuscrito de 1929. Marenitch, A. (Trad.). Educação \& Sociedade, 71, 21-44. 